\title{
ВПЛИВ ФАКТОРІВ ТЕХНОГЕННОГО ТРАНСФОРМОВАНОГО СЕРЕДОВИЩА НА РІВЕНЬ ФЛУКТУЮЧОЇ АСИМТЕРІЇ ЛИСТКОВИХ ПЛАСТИНОК ДЕРЕВНИХ РОСЛИН
}

\author{
У.Й. Семак
}

The influence of technologically transformed environment factors on the level of fluctuation asymmetry of tree plants leaves plates. - Semak U.Y. - One of the most informative methods of integrated assessment of environmental quality is the indicator of fluctuating asymmetry. The level of fluctuating asymmetry, which is a measure of developmental stability, reflects the implementation of ontogenetic programs in specific conditions. The indicator is a reliable bioindication marker of the vital state of plant organisms, as it is minimal in optimal conditions and nonspecifically increases under stress. The paper presents the results of the assessment of the level of fluctuating asymmetry under the conditions of influence of man-caused factors of ash and slag dumps of Burshtyn thermal power station, which is a territory of increased ecological risks. The study analyzed the level of fluctuating asymmetry of leaf blades of the three most common species on the study area-Populus tremula L., Salix caprea L., Betula pendula Roth. An integrated indicator of development stability, which reflects the ecological state of the territory, is determined. The rate of fluctuating asymmetry of leaf blades of the studied species ranged from 0.061 to 0.077. The highest levels of asymmetry were recorded in P. tremula, the lowest - in B. pendula. Among the analyzed foliar indicators, the most unstable features are the indicators of the angles between the first and central veins, the angle between the central and second veins from the base of the leaf blade, as well as the distance between the first and second veins. Based on the integrated indicator of fluctuating asymmetry, the ecological condition of the ash and slag dump territory is assessed as critical. The three most common species were tested in the study area as test objects for bioindication studies using the indicator of fluctuating asymmetry. The results of the analysis allow to place the studied species in the following series of sensitivity to man-caused load in terms of fluctuating asymmetry: B. pendula $\rightarrow$ S. caprea $\rightarrow$ P. tremula. All analyzed species can be used in bioindication studies as sensitive sensors to man-made load.

Keywords: bioindication, technogenic load, foliar parameters, integral asymmetry index.

Address: Vasyl Stefanyk Precarpathian National University, Shevchenko st., 57, Ivano-Frankivsk, Ukraine; e-mail: ulianasemak@gmail.com

Вплив факторів техногенного трансформованого середовища на рівень флуктуючої асиметрії листкових пластинок деревних рослин. - Семак У.Й. - Один із найбільш інформативних методів інтегральної оцінки якості довкілля - показник флуктуючої асиметрії, щь є мірою стабільності розвитку живих організмів та відображає реалізацію їх онтогенетичних програм у конкретних умовах. Цей показник $\epsilon$ надійним біоіндикаціийним маркером життєвого стану рослинних організмів, оскільки неспецифічно зростає при стресі. У статті відображено результати дослідження флуктуючої асиметрії листкових пластинок в умовах впливу техногенних чинників золочлаковідвалів Бурштинської ТЕС, щуо є територією підвищених екологічних ризиків. Проаналізовано рівень флуктуючої асиметрї̈ листкових пластинок трьох найбільш поширених видів дерев Populus tremula L., Salix caprea L., Betula pendula Roth. Визначено інтегральний показник стабільності розвитку, щь відображає екологічний стан території дослідження. Показник флуктуючої асиметрії листкових пластинок досліджуваних видів становив від 0,0610 до 0,0775. Найвищі рівні асиметрії зафіксовано y P. tremula, найнижчі - y B. pendula. Серед аналізованих фоліарних показників найбільш нестійкими ознаками $\epsilon$ значення кутів між першою та центральною жилкою, кут між иентральною та другою від основи листкової пластинки жилкою, а також відстань між першою та другою жилками. На основі інтегрального показника флуктуючої асиметрії екологічний стан території золочлаковідвалів оцінено як критичний. Проведено апробацію трьох найбільи розповсюджених деревних видів на території золошлаковідвалів у якості тестоб'єктів для біоіндикаиійних досліджень із застосуванням показника флуктуючої асиметрії. Результати аналізу дозволяють розташувати досліджувані види у наступний ряд чутливості до техногенного навантаження за ичим показником: B. pendula $\rightarrow$ S. caprea $\rightarrow$ P. tremula. Усі аналізовані види можуть використовуватися у біоіндикаџійних дослідженнях як чутливі сенсори до техногенного навантаження.

Ключові слова: біоіндикація, техногенне навантаження, фоліарні параметри, інтегральний показник acuмeтрї.

Адреса: ДВНЗ «Прикарпатський національний університет ім. Василя Стефаника», вул. Шевченка, 57, ІваноФранківськ, Україна; е-mail: ulianasemak@gmail.com 


\section{Вступ}

Надійним та інформативним методом оцінки впливу факторів техногенезу на стан біоти $\epsilon$ біоіндикаційний підхід. Особливо значимим напрямом біоіндикаційних досліджень $\epsilon$ фітоіндикація, що передбачає діагностику стану екосистем за їх фітокомпонентом.

В умовах впливу факторів техногенного середовища спостерігаються анатомоморфологічні перебудови рослинного організму. Морфологічні модифікації пояснюються тим, що вплив техногенних факторів суттєво перевищує можливості механізмів стійкості біотичних систем (Zakharov et al. 2005). Реакційність морфологічних показників рослин спостерігається як при низьких, так і при високих концетраціях токсикантів (Hrytsak et al. 2017) та може бути зафіксована ще до настання очевидних змін у довкіллі (Pliatsuk 2015). Широко розповсюдженим методом оцінки стану довкілля за морфологічною реакцією фітобіоти $є$ оцінка флуктуючої асиметрії білатеральних структур, насамперед листків (Andreeva 2007; Boiko et al. 2012; Hlukhov et al. 2011; Zakharov et al. 2005). Показник флуктуючої асиметрії $\epsilon$ мірою стабільності розвитку, оскільки асиметричність білатеральних структур мінімальна в оптимальних умовах і неспецифічно зростає при стресі (Hrytsak et al. 2017; Havrykova, Katolichenko 2014; Ibrahimova 2010; Savosko 2014; Leung et al. 200). У стресових умовах механізми, що мали б контролювати симетричність, не здатні забезпечити протистояння негативним зовнішнім впливам (Zakharov et al. 2005; Zoryna, Korosov 2007).

Зростання рівня флуктуючої асиметрії в несприятливих умовах подано у ряді сучасних досліджень (Barabash et al. 2018; Havrykova, Katolichenko 2014; Hlukhov et al. 2011; Zoryna 2012; Pliatsuk 2015; Savosko et al. 2013). Однак окремі спостереження свідчать про відсутність тенденції до зростання асиметрії у стресових умовах (Andreeva 2007; Zoryna 2007; Skliarenko 2019; Sandner et 2019).

Науково обгрунтовано використовувати саме деревні рослини у біоіндикаційних дослідженнях (Andreeva 2007; Pliatsuk 2015; Zverev et al. 2019; Sandner et al. 2019). Популярним об'єктом для фітоіндикації за показником флуктуючої асиметрії листкових пластинок є B. pendula Roth. (Barabash et al. 2018; Zoryna, Korosov 2007; Petrushkevych 2018; Pliatsuk 2015; Skliarenko 2019).

Таким чином, флуктуюча асиметрія як показник дестабілізації онтогенетичних програм рослинних організмів може слугувати індикатором рівня техногенного навантаження.

Мета роботи - здійснити оцінку стану середовища за показником флуктуючої асиметрії типових видів дендробіоти золошлаковідвалів Бурштинської теплоелектростанції (ТЕС).

Актуальність роботи: аналіз флуктуючої асиметрії листкових пластинок досліджуваних видів дасть можливість не тільки діагностувати стан екосистеми промислових територій потенційно небезпечного техногенного об'єкту, а й відобразить чутливість даного показника у різних видів. Оцінка стійкості різних видів дозволить покращити стан довкілля та розробити науково обгрунтовані рекомендації щодо проведення біоіндикаційних досліджень в подальшому.

\section{Матеріал та методика}

Об'єктом дослідження обрано три найбільш розповсюджені на золошлаковідвалах Бурштинської TEC види: P. tremula L., Salix caprea L., Betula pendula Roth. Для досягнення мети дослідження проаналізовано морфологічні особливості листкових пластинок досліджуваних видів рослин та визначено рівень флуктуючої асиметрії; здійснена оцінка екологічного стану території з використанням інтегрального показника стабільності розвитку.

Бурштинська TEC - найбільший забруднювач на території Прикарпаття та джерело ряду потенційно небезпечних полютантів, серед яких - сірчистий і сірчаний ангідриди, оксиди нітрогену, летюча зола, газоподібні продукти неповного згоряння, дрібнодисперсні аерозолі тощо (Mylenka 2009). Найбільш небезпечними полютантами через високу токсичність для біоти є важкі метали (Mylenka 2009; Nespliak 2011). Вплив полютантів позначається на стані фітобіоти в зоні впливу підприємства (Nespliak 2011).

Збір матеріалу проводився в 2017-2019 pр. Відбір зразків здійснювали після закінчення росту, наприкінці вегетаційного періоду. Сумарна вибірка становила 1500 листкових пластинок (по 250 листочків для всіх видів на досліджуваних ділянках золошлаковідвалів та Галицького національного природного парку.

Визначали такі параметри листкової пластинки: 1) ширина половини листка, см; 2) довжина першої жилки від основи листка, см; 3) довжина другої жилки від основи листка, см; 4) відстань між основою першої і другої жилок, см; 5) кут між головною жилкою і першою від 
основи листка жилкою; 5) кут між головною жилкою і другою від основи листка жилкою.

Розрахунки інтегрального значення флуктуючої асиметрії здійснювали за формулою:

$$
\mathrm{K}=\frac{\sum_{i=1}^{n} \quad\left(\left|L_{i}-R_{i}\right|\right) /\left(\left|L_{i}+R_{i}\right|\right)}{n},
$$

де: $\mathrm{L}_{\mathrm{i}}$ - значення виміряного показника з лівого боку листка; $\mathrm{R}_{\mathrm{i}}$ - значення показника 3 правого боку листка; $\mathrm{n}$ - кількість параметрів.
Оцінка екологічного стану дослідних територій на основі показника флуктуючої асиметрії була виконана за шкалою В.М. Захарова (Zakharov 2005). Значення інтегрального показника асиметрії, який відповідає першому балу, характерно для рослин, що зростають у сприятливих умовах; п'ятий бал - свідчить про пригніченість рослин і спостерігається в умовах високих рівнів стресу (табл. 1).

Таблиця 1.Оцінка відхилень стану організму від умовної норми за величиною інтегрального показника стабільності розвитку

Table 1. Estimation of deviations of an organism condition according conditional norm of the integrated indicator value of stability development

\begin{tabular}{|c|c|c|}
\hline Бал & $\begin{array}{c}\text { Величина показника стабільності } \\
\text { розвитку }\end{array}$ & Значення стабільності розвитку \\
\hline I & $<0,040$ & стабільні умови \\
\hline II & $0,040-0,044$ & незначне відхилення від норми \\
\hline III & $0,045-0,049$ & середній рівень відхилення від норми \\
\hline IV & $0,050-0,054$ & значне відхилення від норми \\
\hline V & $>0,054$ & критичний стан \\
\hline
\end{tabular}

Аналіз показників листкових пластинок здійснювали, використовуючи програмний пакет CoralDRAW X6. Статистичну обробку отриманого матеріалу проводили за допомогою пакету програми MS Excel.

\section{Результати та їх обговорення}

За результатами аналізу флуктуючої асиметрії листкових пластинок дослідних видів найбільший рівень цього показника відмічено у $P$. tremula - 0,0775. Найбільш нестійкими ознаками цього виду є кут між другою та цент- ральною жилкою $(0,116)$ та кут між першою та центральною жилкою $(0,095)$, а також відстань між першою та другою від основи листкової пластинки жилками $(0,108)$. Інші ознаки виявились більш стійкими, проте також показали високі рівні флуктуючої асиметрії. В умовах екосистеми, прийнятої за фонову територію, інтегральний показник флуктуючої асиметрії у $P$. tremula становить 0,0406 , а дані показники $\epsilon$ низько- та середньостійкими (табл. 2).

Таблиця 2. Значення інтегрального показника флуктуючої асиметрії

Table 2 . The value of the integral index of fluctuating asymmetry

\begin{tabular}{|c|c|c|c|}
\hline $\begin{array}{c}\text { Дослідна } \\
\text { територія }\end{array}$ & Вид & $\begin{array}{c}\text { Інтегральний показник } \\
\text { флуктуючої асиметрії }\end{array}$ & $\begin{array}{c}\text { Екологічна оцінка } \\
\text { території }\end{array}$ \\
\hline \multirow{2}{*}{$\begin{array}{c}\text { золо- } \\
\text { шлаковідвал №3 }\end{array}$} & Sopulus tremula L. & $0,0776 \pm 0,005$ & критичний стан \\
\cline { 2 - 4 } & Betula pendula Roth. & $0,0735 \pm 0,003$ & $\begin{array}{c}\text { критичний стан }- \text { значне } \\
\text { відхилення від норми }\end{array}$ \\
\hline \multirow{2}{*}{$\begin{array}{c}\text { територія } \\
\text { Галицького } \\
\text { НПП }\end{array}$} & Populus tremula L. & $0,0610 \pm 0,004$ & $\begin{array}{c}\text { стабільні умови }- \text { незначне } \\
\text { відхилення від норми }\end{array}$ \\
\cline { 2 - 4 } & Salix caprea L. & $0,0393 \pm 0,004$ & стабільні умови \\
\cline { 2 - 4 } & Betula pendula Roth. & $0,0394 \pm 0,003$ & стабільні умови \\
\hline
\end{tabular}


Інтегральний показник флуктуючої асиметрії $S$. caprea на території золошлаковідвалів становить 0,0735. Найбільш нестійким показником є відстань між першою та другою жилками $(0,110)$, в умовах мінімізованого стресу цей показник характеризується низьким рівнем $(0,016)$. Високочутливими є показники довжини першої жилки $(0,082)$ та кутові значення: 0,079 для першого кута та 0,064 для другого від основи листкової пластинки кута. На території Галицького НПП інтегральний показник флуктуючої асиметрії S. саргеа становить 0,0394 .
Інтегральний показник флуктуючої асиметрії $B$. pendula в стресових умовах становить 0,0610 . Нестійкими ознаками виду $\epsilon$ кут між першою та центральною жилкою $(0,06)$ та кут між другою i центральною жилкою $(0,058)$, а також довжина першої жилки 0,048 . Дані ознаки в стабільних умовах характеризуються високими та середніми рівнями стійкості, а інтегральний показник флуктуючої асиметрії становить 0,0335 . Результати визначення інтегрального показника флуктуючої асиметрії показані на рисунку 1.

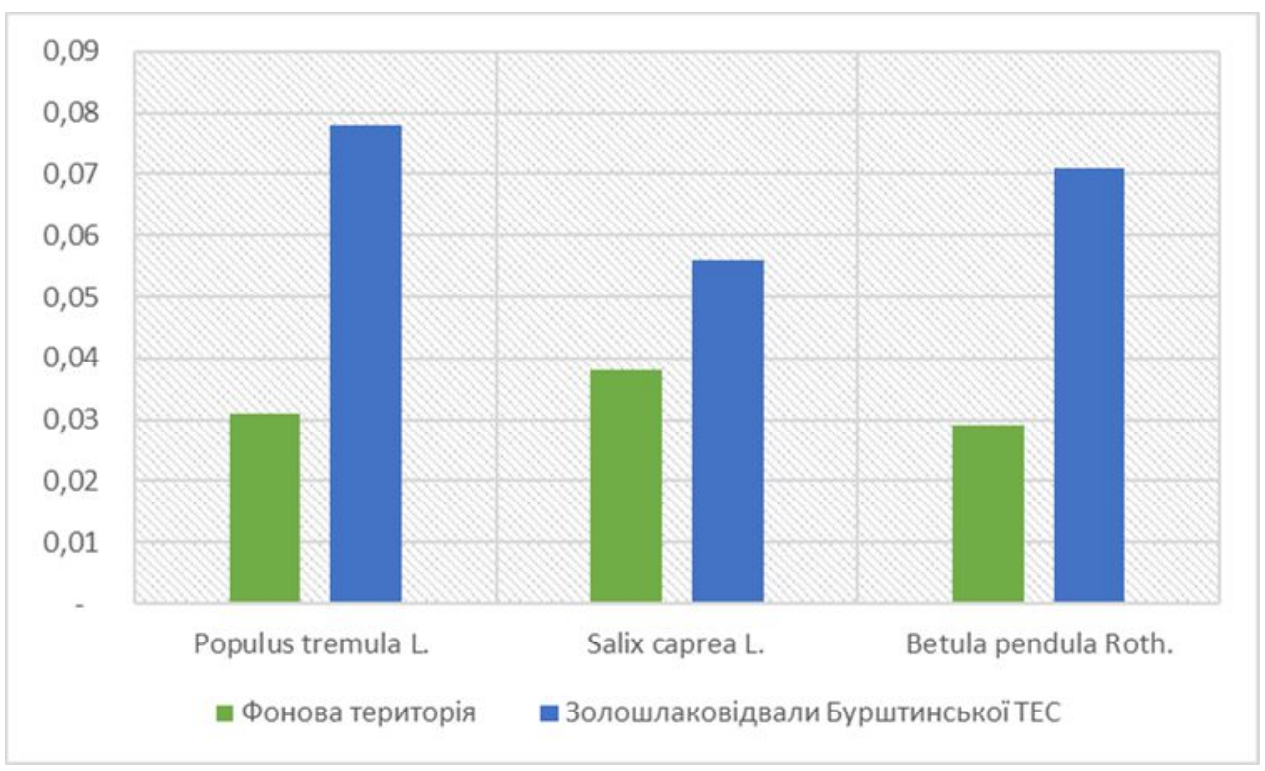

Рис. 1. Інтегральний показник флуктуючої асиметрії досліджуваних видів в умовах золошлаковідвалів Бурштинської ТЕС та на фоновій території

Fig. 1. Integral index of fluctuating asymmetry of the studied species under the conditions of ash and slag dumps of Burshtyn thermal power station and in the background territory

Високі рівні інтегрального показника флуктуючої асиметрії у всіх дослідних видів свідчать про порушення стабільності розвитку рослинних організмів та несприятливу екологічну ситуацію на золошлаковідвалах Бурштинської ТЕС.

\section{Висновки}

Показники флуктуючої асиметрії листкових пластинок деревних видів свідчить про критичний стан екологічної ситуації на золошлаковідвалах Буршинської ТЕС. Встановлено, що середній інтегральний показник для Populus tremula L. становить 0,0776, для Salix caprea L. - 0,0735, найнижчий показник зафіксовано для Betula pendula Roth. 0,0610. Найбільш нестійкими ознаками досліджуваних видів $є$ показники кутів між першою та центральною жилкою, між центральною та другою жилкою, а також показник відстані між першою та другою жилками від основи листкової пластинки. На основі аналізу інтегрального показника флуктуючої асиметрії найбільш високий рівень ушкодженості організму спостерігався у P. tremula. Аналізовані види за чутливістю до факторів техногенного навантаження утворюють ряд: $B$. pendula $\rightarrow S$. caprea $\rightarrow$ P. tremula. Рівень ушкодженості досліджуваних видів дендробіоти за показником флуктуючої асимтерії доцільно враховувати при проведенні фітооптимізації техногенно порушених екотопів золошлаковідвалів Бурштинської ТЕС. 
Таким чином, інтегральний показник флуктуючої асиметрії листкових пластинок деревних видів $є$ чутливим маркером для оцінки стану середовища, а аналізовані види можуть бути використані у біоіндикаційних дослідженнях у якості тест-об'єктів.
ANDREEVA, M.V. (2007) Otsenka sostoianiia okruzhaiushchei sredy $v$ nasazhdenyiakh $v$ zonakh promyshlennykh vybrosov s pomoshchiu rasteniyindikatorov. Avtoreferat dissertatsii kandidata selskokhozyaistvennyh nauk. Sankt-Peterburg. (in Russian).

BARABASH, O.V., LOZOVA, T.M., KOZLOVA, T.A. (2018) Otsinka intensyvnosti antropohennoho vplyvu za rivnem fluktuatsiinoi asymetrii [Assessment of antropogenic influence intensity by the level of fluctuation asymmetry of morphological structures]. Biolohiia ta ekolohia: Naukovyi zhurnal Poltavskoho natsionalnoho pedagogichnogo universytetu im. V.H. Korolenka, 4(166): 72. (in Ukrainian). doi:10.5281/zenodo.1318179

BOIKO, V.V., PLIATSUK, L.D., FILATOV, L.H., TRUNOVA, I.O. (2012) Bioindykatsiina otsinka vplyvu tekhnohennoho navantazhennia vid zabrudnennia atmosfernoho povitria $\mathrm{v}$ umovakh zmin promyslovoi infrastruktury rehionu [Bioindication environment assessment of air pollution in a changing industry infrastructure of the region]. Visnyk KrNU im. Mykhaila Ostrohradskoho, 2(73): 150-153. (in Ukrainian).

HRYTSAK, L.R., BARNA, I., KODLIUK, I., SELSKA, I., SPLAVINSKA, Y., SUKAR, K., BARNA, S. (2017) Bioindykatsiini metody dlia potreb systemnoho analizu yakosti dovkillia [Bioindicative methods for the needs of system analysis of the quality of the environment]. Naukovi zapysky Ternopilskoho natsionalnoho pedahohichnoho universytetu im. Volodymyra Hnatiuka. Seriia: Heohrafiia, 2: 153-165. (in Ukrainian).

HAVRYKOVA, V.S. (2014) Bioindykatsiia urboseredovyshcha za pokaznykom fluktuiuchoi asymetrii derev Acer saccharinum L. [Bioindication of urbanized environment using fluctuating asymmetry index of Acer saccharinum L.]. Naukovo-praktychnyi zhurnal. Ekolohichni nauky, 6: 77-81. (in Ukrainian).

HLUKHOV, A.Z., SHTYRTS, Y.A., DEMKOVYCH, A.E., ZHUKOV, S.P. (2011) Otsenka proyavleniya fluktuiruyushchei assimetrii bilateralnykh priznakov listovoi plastinki Acer pseudoplatanus L. V usloviiakh pridorozhnykh ekosistem promyshlennogo goroda (na primere g. Donetska) [The assessment of the display of fluctuating asymmetry of bilateral features of Acer pseudoplatanus L. leaves in conditions of roadside ecosystems in the industrial city (on the example of Donetsk)]. Promyshlennaia botanyka, 11: 90-96. (in Russian).

ZAKHAROV, V.M., SHKYL, F.N., KRIAZHEVA, N.H. (2005) Otsenka stabilnosti razvitiya berezy $\mathrm{V}$ raznykh chastiakh areala. Vestnik
Nizhehorodskogo universiteta im. N.N. Lobachevskogo. Seriya Biologiya, 1(9): 77-84. (in Russian).

ZORYNA, A.A., KOROSOV, A.V. (2007) Kharakteristika fluktiruiushchei assimetrii lista dvukh vidov berez $v$ Karelii [Characteristics of the fluctuating leaf asymmetry in two birch species in Karelia]. Ekologiya. Eksperimentalnaia genetika $i$ fiziologiya: trudy Karelskogo nauchnogo tsentra $R A N, 11: 28-36$. (in Russian).

ZORYNA, A.A. (2012) Metody statisticheskoho analiza fluktuiruiushchei asymmetrii [Methods of statistical analysis of fluctuating asymmetry]. Printsipy ekologii, 3: 23-45. (in Russian).

IBRAHIMOVA, E.E. (2010) Vliyanie tekhnogennogo khimicheskogo zagriazneniya na velichinu fluktuiruiushchei assimetrii listovoy plastinki Armeniaca vulgaris L. [Influence of technogenic chemical pollution on size of fluctuating asymmetry of the leaf laminae on Armeniaca vulgaris L.]. Uchenye zapiski Tavricheskogo natsionalnogo universiteta im. V.Y. Vernadskogo, Seriya «Biologiya, khimiya», 3: 62-67. (in Russian).

MYLENKA, M.M. (2009) Bioindykatsiina otsinka ekolohichnoho stanu Burshtynskoi urboekosystemy. Avtoreferat dysertatsii kandydata biolohichnyh nauk. Dnipropetrovsk. (in Ukrainian).

NESPLIAK, O.S. (2011) Ekolohichni osoblyvosti formuvannia flory i roslynnosti zoloshlakovidvaliv Burshtynskoi teplovoi elektrostantsii ta yikh vykorystannia v rekultyvatsii. Avtoreferat dysertatsii kandydata biolohichnyh nauk. Dnipropetrovsk. (in Ukrainian).

PETRUSHKEVYCH, Y.M. (2018) Vplyv promyslovykh umov na velychynu fluktuiuchoi asymetrii lystkovoi plastynky Betula pendula [Influence of industrial conditions on the fluctuating asymmetry magnitude of leaf blade of Betula pendula]. Naukovi zapysky Ternopilskoho natsionalnoho pedahohichnoho universytetu im. Volodymyra Hnatiuka. Seriia: Biolohiia, 1: 82-89. (in Ukrainian).

PLIATSUK, D.L. (2015) Provedennia intehralnoi ekspres-otsinky yakosti atmosfernoho povitria $\mathrm{V}$ umovakh zminy promyslovoi infrastruktury rehionu. Vostochno-Evropeiskyi zhurnal peredovykh tekhnolohiy, 3(6): 58-63. (in Ukrainian). doi:10.15587/1729-4061.2015.43753

SAVOSKO, V.M., KATOLICHENKO, O.M. (2014) Fliuktuiucha asymetriia lystkiv berezy povysloi $\mathrm{V}$ umovakh aerotekhnohennoho zabrudnennia Kryvorizhzhia [Fluctuating asymmetry of leave's Silver birch in conditions of air pollution at Kryvorizhzhya]. Pytannia bioindykatsii ta ekolohii, 19(2): 90-102. (in Ukrainian). 

$\begin{array}{llr}\text { SAVOSKO, V.M., } & \text { DOMSHYNA, K.M., } \\ \text { SAVOSKO, V.V. (2013) } & \text { Morfolohichni osoblyvosti }\end{array}$ lystkiv berezy povysloi kulturdendrotsenoziv stepu v umovakh promyslovoho mista [Morphological traits of weeping birch leaves of cultural dendrocenoses of steppe in conditions of industrial city]. Pytannia bioindykatsii ta ekolohii, 18(2): 121-133. (in Ukrainian).

SKLIARENKO, A.V. (2019) Otsiniuvannia vplyvu promyslovykh umov na velychynu fluktuiuchoi asymetrii lystkovoi plastynky Betula pendula Zaporizhzhia [Assessing the impact of industrial conditions on the level of fluctuating asymmetry of the Betula pendula leaf blade in the city of Zaporizhzhia]. Naukovyi visnyk NLTU Ukrainy, 29(6): 54-57. (in Ukrainian). doi:https://doi.org/10.15421/40290611

ZVEREV, V., LAMA, A., KOZLOV, M. (2018) Fluctuating asymmetry of birch leaves did not increase with pollution and drought stress in a controlled experiment. Ecological indicators, 84: 283-289.

SANDNER, T.M., ZVEREV, V., KOZLOV, M.V. (2019) Can the use of landmarks improve the suitability of fluctuating asymmetry in plant leaves as an indicator of stress. Ecological indicators, 97: 457465.

LEUNG, B., FORBES, M.R., HOULE, D. (2000) Fluctuating Asymmetry as a Bioindicator of Stress: Comparing Efficacy of Analyses Involving Multiple Traits. The American Naturalist, 155(1): 101-115. 